\title{
Assessing Emotions Related to Privacy and Trust in Personalized Services
}

\author{
Ilias O. Pappas ${ }^{1}$, Michail N. Giannakos ${ }^{2}$, Panos E. Kourouthanassis ${ }^{1}$, \\ and Vassilios Chrissikopoulos ${ }^{1}$ \\ ${ }^{1}$ Department of Informatics, Ionian University, Corfu, Greece \\ \{ilpappas, pkour, vchris\} @ionio.gr \\ ${ }^{2}$ Department of Computer and Information Science, \\ Norwegian University of Science and Technology (NTNU) \\ michail.giannakos@idi.ntnu.no
}

\begin{abstract}
This study explores the dynamics of personalized services in online shopping, with regard to emotions, privacy and trust. The basic emotions of happiness and anxiety were chosen. A sample of 182 online shoppers was used to assess the effect of privacy and trust on their emotions through personalized services, and how these emotions ultimately affect their purchase intentions. The findings indicate that privacy affects anxiety while trust affects happiness, while both emotions have significant influence on customers' intention to buy through personalized services. The study concludes with theoretical and practical implications, limitations, and future research directions.
\end{abstract}

Keywords: Personalization, emotions, privacy, trust, anxiety, happiness, intention.

\section{Introduction}

Advances in technology give the opportunity to online vendors to offer high level of personalization, which can be used to communicate with customers in different levels. The collection and use of transactional, demographic and behavioral data makes it a great way to offer personalized services to every customer. Online vendors may offer a friendlier and individualized shopping experience, which eventually might increase customers' loyalty [1]. Online personalization has not been extensively addressed regarding customers' behavior [2].

Personalized services are based on customers' personal and private information, so if a customer wants to use such services he is obligated to share them. However, a level of trust that the service provider will behave ethically should exist. At the same time privacy concerns should be accounted for since they start affecting customers almost as soon as they share their data, reducing their purchase intentions [3]. The collection and use of private information have caused serious concerns about privacy invasion by customers [4] Previous studies have found that online shopping behavior is affected from customers' emotions [5]. Emotions, as a predictor of Information 
Technology use [6], may be a result of using personalized services. Although positive and negative emotions have been found to affect post purchase intentions [7], their role in personalized services still remains understudied.

This study provides a first insight into what factors affect the provision of personalized services in e-commerce environments. Previous studies have identified the importance of personalization in online shopping [8]. Likewise, scholars have shed light on the factors that affect adoption behavior of personalization [9]. Nevertheless, the role of emotions on this adoption behavior remains largely understudied. Drawn on the above, the objectives of this study are two-fold. On the one hand, we seek to investigate how happiness and anxiety affect adoption behavior of personalized services. On the other hand, we explore how privacy and trust issues shape the formulation of emotions on personalized environments. Privacy and trust issues are considered in an attempt to explain their relation with happiness and anxiety, and how these emotions affect customers' intentions. To this end, an empirical model is proposed and tested using structural equations modeling (SEM).

This paper is organized as follows. In the next section we review the existing literature on privacy, trust, happiness, anxiety and intention to purchase. In section 3 , we present the theoretical foundation of the research model. In section 4, we present the methodology and the measures adopted for collecting data on the online shopping behavior. Section 5 presents the empirical results derived. In the last section of the paper, we discuss the findings and conclude by providing theoretical and practical implications and make recommendations for future research.

\section{$2 \quad$ Literature Review}

Online personalization refers to providing customers with tailored content and services based on knowledge obtained through service and user interactions [10]. In this study we employ the definition of Roberts [11] who defines personalization as "the process of preparing an individualized communication for a specific person based on stated or implied preferences" (p.462). Previous studies have identified the importance of personalization in online shopping and its effect on customers' behavior [2][12]. In order for personalization to be successful and to achieve its main goal, which is satisfied customers, different factors need to be taken into account. A vast overview on the subject is provided from Adoplhs and Winkelman [9], including user centric aspects, implementation and theoretical foundations. Nevertheless, emotions are not included.

In the ever growing field of online shopping customers' emotional reactions are common. Hedonic motivations have been found to affect customers' shopping online experience and their future intentions [13]. The different emotions that arise from online shopping can be affected or triggered by using personalized services. However, there is limited research on the different emotional aspects that occur from online shopping [14]. It has been argued that emotions are constituted of different constructs, although it is generally agreed that at least four are the basic emotions, namely 
happiness, sadness, anxiety and anger [15]. Our study adopts the emotional constructs from Kay and Loverock [15]. Specifically we examine happiness and anxiety. Happiness is defined as the extent to which a person feels satisfied, excited and curious. Anxiety refers to the extent to which a person feels anxious, helpless, nervous and insecure.

People are expected to avoid behaviors that create anxious feelings and prefer those that give them happiness. In the more general area of IT use, happiness has been found to affect IT use positively, but a negative effect was found on task adaptation, which refers to how the user modifies they way something is done based on the technology used [6]. In other words, users are less happy when they have to change their personal preferences on how they complete a task in order to gain more benefits. Regarding anxiety, it was found a direct negative effect on IT use, and an indirect positive effect on IT use through social support [6]. This means that when users as for help from people they personally know (i.e. family, friends), their anxiety has a lower effect on IT use. It can be inferred that when the service is offered personally to a user, while based on individual preferences and tailored to the his needs, his anxiety will be reduced.

Previous studies point out the importance of anxiety while using computers [3]. Specifically, low levels of anxiety lead to more positive attitudes towards information sharing, essential for personalization. Moreover, anxiety has a negative effect on customers' intention to use mobile shopping [16]. In the context of computer learning, previous studies have found that higher levels of happiness and lower levels of anxiety may lead to increased computer use [15]. Anxiety has been studied extensively, focusing on system or computer anxiety [17]. However, anxiety in the context of personalized services is understudied.

Anxiety is very interesting to study as it provides insight into customers' general concerns regarding privacy [3]. Moreover, in order to develop long-term relationships with their customers, it is important for e-retailers to both develop and nurture consumer trust [18]. Both privacy and trust have been examined in the general context on online shopping, however their effects on basic emotions such as happiness and anxiety are understudied. Additionally, previous studies have examined the effect of privacy on personalization and information sharing. Collecting and using private information for personalization purposes has increased the privacy concerns of the customers [4]. It is proposed that if customers are given control over the use of their data, they are willing to share them because they feel their privacy will not be violated [3]. However, Brandimarte et al (2012)[19] found that offering users high control of their private data does not always lead to high privacy protection, because the sense of security that is created leads them to share even more information to a wider audience. The effects of privacy and trust on emotions need to be studied when customers use personalized services, because they might change depending on the offered services; how the services are offered, what they include and what the customer has to gain from them [20-22]. 


\section{Hypotheses and Model Development}

The aim of this study is twofold. First, we investigate the effects of privacy and trust on both happiness and anxiety. Next, we assess the effects of happiness and anxiety on intention to purchase while using personalized services.

\subsection{Do Privacy Issues Shape Our Emotions?}

Privacy is important for a customer that wants to create a relationship with an online vendor. Taking into account that personalized services are based on customers' personal data, privacy concerns become even more important in this relation. Lee and Cranage [23], examined the personalization-privacy paradox, where the better services a customer wants the more personal information he has to share, and found that high privacy issues increase customers' unwillingness to share such information and reduce their future intentions. On the other hand, customers are more willing to reveal personal data when they feel they can control their future use [3]. Pappas et al. [20] posit that high privacy concerns towards personalized services reduce customers' enjoyment, while $\mathrm{Xu}$ et al. [21] found that using personalized services might help customers to override their privacy concerns. Nonetheless, privacy issues towards online shopping, affect anxiety, which is likely to reduce customers' positive feelings [17]. Hence, we propose that:

H1: Privacy will have a negative effect on happiness.

H2: Privacy will have a positive effect on anxiety.

\subsection{Do Trust Issues Shape Our Emotions?}

Trust is critical for an online vendor to be successful, especially when personalized services are offered. Hwang and Kim [17] found that customers' affective reactions are related with trust. When referring to trust emotions are present [24]. Previous studies have showed that depending on the customers' involvement with an online vendor, factors such as satisfaction are decisive when fostering trust [25]. Taking into account that in order for personalized services to work, customers' involvement is needed and that satisfaction is closely related with emotions we propose that:

H3: Trust will have a positive effect on happiness.

H4: Trust will have a negative effect on anxiety.

\subsection{How Emotions Influence Our Purchase Intentions?}

Different emotions arise during consumption and affect customers' behavior. These emotions might either be positive or negative. Previous studies have showed that emotions' effect on intention might either be positive or negative [5][26]. Koo and Ju [27] found that pleasure and arousal that derive from atmospherics affect positively online shopping intention. Moreover, in the context of mobile shopping services anxiety was found to affect negatively behavioral intentions [15]. Besides, the more generalized positive and negative emotions, it is essential to examine the specific types-categories of emotions and how they affect customers' intentions while using personalized services. Consequently, we propose that: 
H5: Happiness will have a positive effect on intention to purchase.

H6: Anxiety will have a negative effect on intention to purchase.

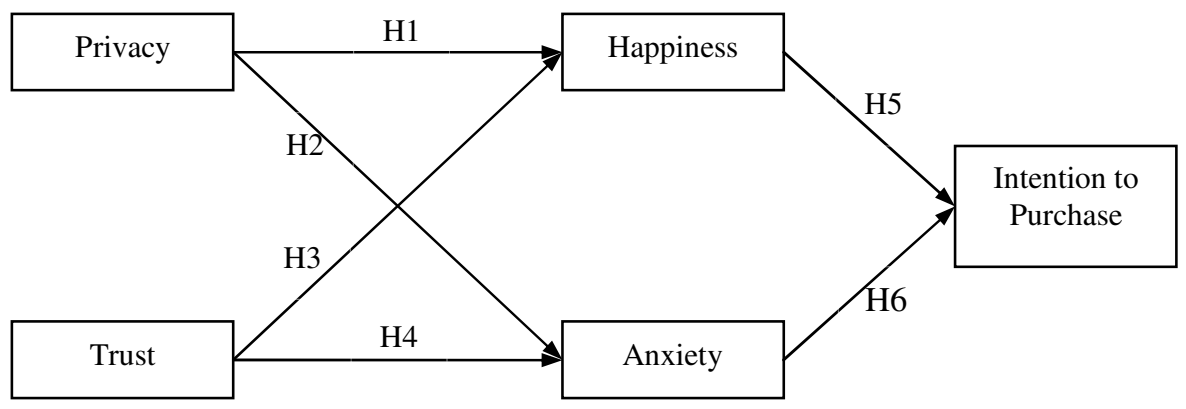

Fig. 1. Research Model

\section{Methodology}

\subsection{Sample}

Our research methodology included a survey conducted through the delivery and collection of individual questionnaires. It was made clear that there was no reward for the respondents and the participation was voluntary. The survey was executed in June-July 2012. We aimed at 600 (Greek) users of online shopping, 182 of which finally responded.

Table 1. Users' demographic profile

\begin{tabular}{|l|l|c|l|}
\hline \multicolumn{2}{|c|}{ Demographic Profile } & No & \multicolumn{1}{c|}{$\%$} \\
\hline \multirow{3}{*}{ Gender } & Male & 98 & $53.8 \%$ \\
& Female & 84 & $46.2 \%$ \\
\hline \multirow{3}{*}{ Marital } & Single & 132 & $72.5 \%$ \\
Status & Married & 45 & $24.7 \%$ \\
& Divorced & 5 & $2.7 \%$ \\
\hline \multirow{5}{*}{ Age } & $0-24$ & 52 & $28.6 \%$ \\
& $25-29$ & 56 & $30.8 \%$ \\
& $30-39$ & 44 & $24.2 \%$ \\
& $40+$ & 30 & $16.5 \%$ \\
\hline \multirow{5}{*}{ Education } & Middle School & 2 & $1.1 \%$ \\
& High School & 22 & $12.1 \%$ \\
& University & 78 & $42.9 \%$ \\
& Post Graduate & 80 & $44 \%$ \\
\hline
\end{tabular}


As Table 1 shows, the sample of respondents was composed of almost equally men $(53.8 \%)$ and women (46.2\%). In terms of age, the majority of the respondents $(30.8 \%)$ were between 25 and 29 years old, $25.3 \%$ involved people between 18 and 24 and $24.2 \%$ were between 30 and 39 . Finally, the vast majority of the respondents $(86.9 \%)$ included graduates or post-graduate students.

\subsection{Measures}

The questionnaire was divided into two parts. The first part included questions on the demographics of the sample (age, marital status, gender, education). The second part included measures of the various constructs identified in the literature review section. Table 2 lists the operational definitions of the constructs in this theoretical model, as well as the studies from which the measures were adopted. The appendix lists the questionnaire items used to measure each construct. We employed a 7-point Likert scale anchored from 1 ("completely disagree") to 7 ("completely agree").

Table 2. Construct definition and instrument development

\begin{tabular}{|c|l|c|}
\hline Construct & \multicolumn{1}{|c|}{ Operational Definition } & Source \\
\hline Privacy (PR) & $\begin{array}{l}\text { Measuring the customers' privacy issues when } \\
\text { using personalized services. }\end{array}$ & {$[26]$} \\
\hline Trust (TR) & $\begin{array}{l}\text { Measuring the customers' trust issues when } \\
\text { using personalized services. }\end{array}$ & {$[27]$} \\
\hline Happiness (HAP) & $\begin{array}{l}\text { Measuring the customers' happiness when } \\
\text { using personalized services. }\end{array}$ & {$[15]$} \\
\hline Anxiety (ANX) & $\begin{array}{l}\text { Measuring the customers' anxiety when using } \\
\text { personalized services. }\end{array}$ & {$[15]$} \\
\hline $\begin{array}{c}\text { Intention to Purchase } \\
\text { (INT) }\end{array}$ & $\begin{array}{l}\text { Customers' intention to shop online based on } \\
\text { personalized services }\end{array}$ & {$[28-29]$} \\
\hline
\end{tabular}

\subsection{Data Analysis}

Structural equation modeling was conducted using AMOS version 18.0 software, based on Byrne [32]. At first, a measurement model was created based on a confirmatory factor analysis, and then the structural model was built in order to test the hypothesized relationships.

Goodness of fit describes how well the model fits its data. Here, several fit indices were used to assess model-data fit. Root mean square error of approximation (RMSEA), comparative fit index (CFI) and $\chi 2 / \mathrm{df}$ ratio were all used to evaluate model-data fit (Byrne, 2009). RMSEA less than 0.05 suggests good model-data fit; between 0.05 and 0.08 it suggests reasonable model-data fit and between 0.08 and 0.01 suggests acceptable model data fit. CFI indices greater than 0.90 suggest good modeldata fit and greater than 0.80 suggest adequate model-data fit. A $\chi 2 /$ df ratio less than 3 is acceptable. 


\section{$5 \quad$ Findings}

First, an analysis of reliability and validity was carried out. Reliability testing, based on the Cronbach alpha indicator, shows acceptable indices of internal consistency since all constructs exceed the cut-off threshold of 0.70. The AVE for all constructs ranges between 0.681-0.805, exceeding the cut-off threshold of 0.50 . Finally, all correlations are lower than 0.80 and square root AVEs for all constructs are larger from their correlations. Our findings are illustrated in Table 3.

Table 3. Descriptive statistics and correlations of latent variables

\begin{tabular}{|c|c|c|c|c|c|c|c|c|c|}
\hline \multicolumn{9}{|c|}{} & \multicolumn{6}{|c|}{ Construct } \\
\hline Construct & Mean & SD & CR & AVE & PR & TR & HAP & ANX & INT \\
\hline PR & 5.35 & 1.63 & 0.923 & 0.813 & $\mathbf{0 . 9 0 2}$ & & & & \\
\hline TR & 3.05 & 1.44 & 0.896 & 0.745 & $-0.153 *$ & $\mathbf{0 . 8 6 3}$ & & & \\
\hline HAP & 3.84 & 1.46 & 0.769 & 0.564 & $-0.120^{*}$ & $0.386 * *$ & $\mathbf{0 . 7 5 1}$ & & \\
\hline ANX & 2.97 & 1.44 & 0.838 & 0.567 & $0.205 * *$ & $-0.123 *$ & $0.167 *$ & $\mathbf{0 . 7 5 2}$ & \\
\hline INT & 4.05 & 1.66 & 0.939 & 0.630 & $-0.203 * *$ & $0.388^{* *}$ & $0.601 * *$ & $-0.161 *$ & $\mathbf{0 . 7 9 4}$ \\
\hline
\end{tabular}

Note: Diagonal elements (in bold) are the square root of the average variance extracted (AVE). Off-diagonal elements are the correlations among constructs (all correlations are significant, $\left.{ }^{*} \mathrm{p}<0.01 ;{ }^{*} \mathrm{p}<0.05\right)$. For discriminant validity, diagonal elements should be larger than off-diagonal elements. PR, Privacy; TR, Trust; HAP, Happiness; ANX, Anxiety; INT, Intention to Purchase.

The fit indices of the research model are presented on table 4. All values are within the recommended range. Specifically, $\chi 2 / \mathrm{df}=1.96, \mathrm{CFI}=0.96$ and $\mathrm{RMSEA}=0.07$.

Table 4. Overall model fit indices for the structural model

\begin{tabular}{|c|c|c|}
\hline Model fit indices & Results & Recommended value \\
\hline$\chi^{2} / \mathrm{df}$ & $1.96(\mathrm{x} 2=; \mathrm{df}=)$ & $<=3$ \\
\hline CFI & 0.96 & $>=0.9$ \\
\hline RMSEA & 0.07 & $<=0.08$ \\
\hline
\end{tabular}

The estimated path coefficients of the structural model were examined in order to evaluate our hypotheses. Figure 2 presents the analysis of the research model. Specifically, privacy has a positive effect on anxiety, supporting H2. On the other hand, privacy has no significant effect on happiness, rejecting H1. Regarding trust, a positive effect on happiness was found, supporting $\mathrm{H} 3$, while there was no significant effect on anxiety. Next, both happiness and anxiety were found to affect significantly intention to purchase. Happiness's effect on intention is positive, supporting H5, while anxiety's effect is negative, supporting H6. Square multiple correlations (R2) 
are presented on figure 2 as well. The R2 for happiness was 0.43 , for anxiety was 0.1 and that of intention to purchase was 0.85 . Values higher than 0.26 , imply high effect of the predictors of positive emotions and intention to purchase respectively.

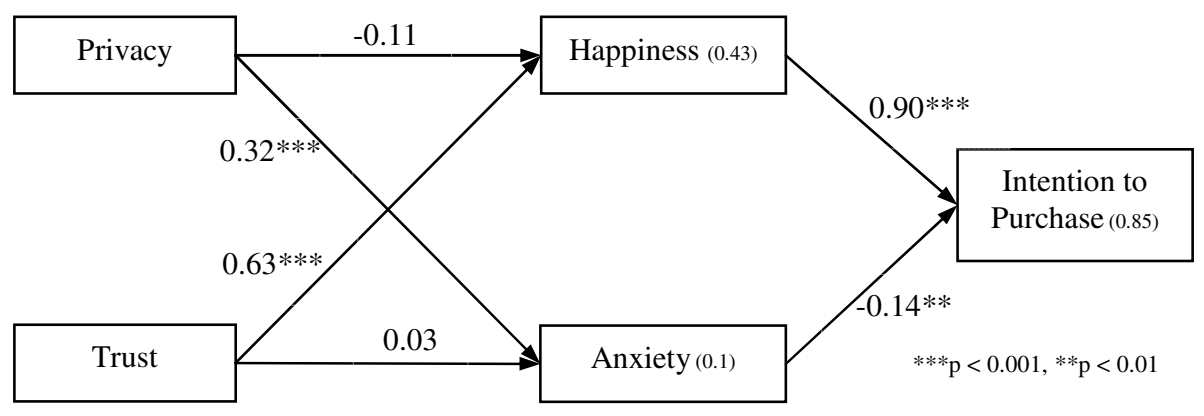

Fig. 2. SEM Analysis of the research model

\section{Discussion and Conclusions}

This study emphasizes on how the use of personalized services affects customers' intentions to proceed to online purchase. We investigate the effects of privacy and trust on the formulation of two critical emotional factors, namely happiness and anxiety, and the effect of the two emotional factors on purchase intention. Our results indicate that privacy and trust affect partially the emotional factors examined in this study. Specifically, privacy affects positively anxiety but has no effect on happiness. On the other hand, trust affects positively happiness but has no effect on anxiety. Moreover, happiness was found to have a very high positive effect on intention to purchase, while anxiety had a negative effect on intention to purchase.

Our study revealed that privacy issues have no effect on happiness, while a negative effect was expected, which may be due to the fact that the respondents shared their personal and private data willingly and might expect some privacy violations. Privacy was found to have a positive effect on anxiety, which was expected as for a customer with high privacy concerns, being unsure of how the information he shared with an online vendor are used, while it is the only way to use personalized services, makes him feel insecure, helpless and nervous. On one hand, our findings regarding the effects on happiness, which a positive emotion, contradict with previous studies that have found privacy to affect negatively one other positive emotion, that of enjoyment [20]. On the other hand, our findings regarding the effects on anxiety are consistent with previous studies that found high privacy concerns to be positively related with anxious customers [3]. In the case of trust, we found that it has a positive effect on happiness, but has no effect on anxiety. As expected, when users trust the online vendor are less worried about sharing their personal and private information and using the personalized services, which makes them feel more satisfied and excited. However, the insignificant effect of trust on anxiety was unexpected, which may be attributed to the fact that trust is not related with negative feelings, but it is the 
factor of distrust that creates them [33]. Hwang and Kim [17] found a positive relation among trust and enjoyment, similar to our findings, but they found a negative relation between trust and anxiety, which contradicts with our results.

The basic emotions examined on this study, were both found to affect customers' intention to purchase. Happiness had a positive effect on intention as expected, because the more satisfied and excited are customers with personalized services, the more likely is that they will want to make purchases. Similarly, was found that anxiety has a negative effect on intention, as the more insecure, helpless and nervous a customer feels the less likely is that he will proceed to purchases. Our findings are consistent with $\mathrm{Lu}$ and $\mathrm{Su}$ [15], who found enjoyment to have a positive effect on intention and anxiety to have a negative effect on intention. Moreover, our results regarding personalized services as an Information Technology are consistent with Beaudry \& Pinsonneault [6], who studying IT use found happiness to affect IT positively and anxiety to affect IT negatively,

Our empirical research has addressed several shortcomings of previous studies in the area. Schwaig et al. [3], studying customers' privacy, although they include anxiety in their research, they do not consider factors of positive emotions like happiness. Moreover, Lee and Cranage [23], examine personalization and privacy but do not consider any emotional factors in their study, factors which have been proved to affect both highly. Pappas et al. [20], while investigating the effects of privacy and enjoyment when using personalized services, they do not investigate any negative emotions. Positive and negative emotions should be studied together as they may have different effects on customers' behavior [34].

The present study is one of the few so far that explores customers' basic emotions while using personalized services for online shopping. We investigate how these emotions influenced by privacy and trust combine to affect customers' intention to purchase. Since this area is understudied, the proposed model shows an acceptable level of explaining how privacy, trust, happiness, anxiety and intention to purchase relate in order to fill this gap. Previous studies on online shopping have identified the importance of negative emotions over the positive. For example, a customer will be more influenced by reading a negative review for an online vendor than reading a positive one. However, using personalized services seems to change that, since positive emotions, and specifically happiness, are those that affect mostly customers' intention.

The findings of this study reveal that emotions affect customers' intentions to purchase through personalized services, with happiness having a much higher impact on intention. Hence, service providers should focus on customers' emotional responses in order to understand their intentions and change the way they communicate with their customers accordingly. Moreover, online vendors that offer personalized services should primarily target happiness over anxiety. Consequently, online vendors should try to increase customers' trust towards them since only trust was found to affect happiness.

As with any empirical study, there are some limitations. Firstly, in this study the sample used is highly educated (university and post graduates) and is expected to be familiar with online services. Also, our results are based on self-reported data so customers actually behavior might be different. Future studies should include other 
methods; observation, interviews and web log file analysis in order to provide a better understanding of customers' experience. Moreover, we include in our study only the two basic emotions that have been identified from the literature as the most important. Following studies should include anger and sadness for a more thorough study. Finally, since privacy affects only anxiety and trust affects only happiness, future research should examine both privacy and trust as one factor and study their interrelation.

\section{References}

1. Zhou, L., Dai, L., Zhang, D.: Online shopping acceptance model - A critical survey of consumer factors in online shopping. Journal of Electronic Commerce Research 8, 41-62 (2007)

2. Lee, E.J., Park, J.K.: Online service personalization for apparel shopping. Journal of Retailing and Consumer Services 16, 83-91 (2009)

3. Schwaig, K.S., Segars, A.H., Grover, V., Fiedler, K.D.: A Model of Consumers' Perceptions of the Invasion of Information Privacy. Information \& Management (2012), doi:10.1016/j.im.2012.11.002

4. Lee, D.J., Ahn, J.H., Bang, Y.: Managing consumer privacy concerns in personalization: a strategic analysis of privacy protection. MIS Quarterly 35, 423-444 (2011)

5. Penz, E., Hogg, M.K.: The role of mixed emotions in consumer behaviour: Investigating ambivalence in consumers' experiences of approach-avoidance conflicts in online and offline settings. European Journal of Marketing 45, 104-132 (2011)

6. Beaudry, A., Pinsonneault, A.: The other side of acceptance: studying the direct and indirect effects of emotions on information technology use. MIS Quarterly 34, 689-710 (2010)

7. Kuo, Y.F., Wu, C.M.: Satisfaction and post-purchase intentions with service recovery of online shopping websites: Perspectives on perceived justice and emotions. International Journal of Information Management 32, 127-138 (2012)

8. Kwon, K., Cho, J., Park, Y.: How to best characterize the personalization construct for eservices. Expert Systems With Applications 37, 2232-2240 (2010)

9. Adolphs, C., Winkelmann, A.: Personalization Research in E-Commerce - A State of the Art Review (2000-2008). Journal of Electronic Commerce Research 11, 326-341 (2010)

10. Adomavicius, G., Tuzhilin, A.: Personalization technologies: a process-oriented perspective. Communications of the ACM 48, 83-90 (2005)

11. Roberts, R.C.: Emotions: An essay in aid of moral psychology. Cambridge University Press (2003)

12. Zhang, H., Lu, Y., Shi, X., Tang, Z., Zhao, Z.: Mood and social presence on consumer purchase behaviour in C2C E-commerce in Chinese culture. Electronic Markets, 1-12 (2012)

13. Chiu, C.M., Wang, E.T.G., Fang, Y.H., Huang, H.Y.: Understanding customers' repeat purchase intentions in $\mathrm{B} 2 \mathrm{C}$ e-commerce: the roles of utilitarian value, hedonic value and perceived risk. Information Systems Journal (2012)

14. Ethier, J., Hadaya, P., Talbot, J., Cadieux, J.: Interface design and emotions experienced on B2C Web sites: Empirical testing of a research model. Computers in Human Behavior 24, 2771-2791 (2008)

15. Lu, H.P., Su, P.Y.J.: Factors affecting purchase intention on mobile shopping web sites. Internet Research 19, 442-458 (2009)

16. Kay, R.H., Loverock, S.: Assessing emotions related to learning new software: The computer emotion scale. Computers in Human Behavior 24, 1605-1623 (2008) 
17. Hwang, Y., Kim, D.J.: Customer self-service systems: The effects of perceived Web quality with service contents on enjoyment, anxiety, and e-trust. Decision Support Systems 43, 746-760 (2007)

18. Palvia, P.: The role of trust in e-commerce relational exchange: A unified model. Information \& Management 46, 213-220 (2009)

19. Brandimarte, L., Acquisti, A., Loewenstein, G.: Misplaced confidences: Privacy and the control paradox. Social Psychological and Personality Science (2013)

20. Pappas, I.O., Giannakos, M.N., Chrissikopoulos, V.: Personalized services in online shopping: Enjoyment and privacy. In: 2012 International Conference on Information Society (iSociety), pp. 168-173. IEEE (2012)

21. Xu, H., Luo, X.R., Carroll, J.M., Rosson, M.B.: The personalization privacy paradox: An exploratory study of decision making process for location-aware marketing. Decision Support Systems 51, 42-52 (2011)

22. Dabholkar, P.A., Sheng, X.: Consumer participation in using online recommendation agents: effects on satisfaction, trust, and purchase intentions. The Service Industries Journal 32, 1433-1449 (2011)

23. Lee, C.H., Cranage, D.A.: Personalisation-privacy paradox: The effects of personalisation and privacy assurance on customer responses to travel Web sites. Tourism Management 32, 987-994 (2011)

24. Young, L.: Trust: looking forward and back. Journal of Business \& Industrial Marketing 21, 439-445 (2006)

25. Martín, S.S., Camarero, C., José, R.S.: Does involvement matter in online shopping satisfaction and trust? Psychology and Marketing 28, 145-167 (2011)

26. Shen, J.: Social Comparison, Social Presence, and Enjoyment in the Acceptance of Social Shopping Websites. Journal of Electronic Commerce Research 13, 198-212 (2012)

27. Koo, D.M., Ju, S.H.: The interactional effects of atmospherics and perceptual curiosity on emotions and online shopping intention. Computers in Human Behavior 26, 377-388 (2010)

28. Ho, S.Y., Ho, K.K.W.: The Effects of web personalization on influencing users' switching decisions to a new website. In: PACIS 2008 Proceedings. Paper 67 (2008)

29. Ray, S., Ow, T., Kim, S.S.: Security Assurance: How Online Service Providers Can Influence Security Control Perceptions and Gain Trust. Decision Sciences 42, 391-412 (2011)

30. Chen, Y.T., Chou, T.Y.: Exploring the continuance intentions of consumers for B2C online shopping: Perspectives of fairness and trust. Online Information Review 36, 104-125 (2012)

31. Lu, Y., Cao, Y., Wang, B., Yang, S.: A study on factors that affect users' behavioral intention to transfer usage from the offline to the online channel. Computers in Human Behavior 27, 355-364 (2011)

32. Byrne, B.: Structural Equation Modeling With AMOS: Basic Concepts, Applications, and Programming. Taylor \& Francis (2009)

33. McKnight, D.H., Choudhury, V.: Distrust and trust in B2C e-commerce: Do they differ? In: 8th International Conference on Electronic Commerce: The New E-Commerce: Innovations for Conquering Current Barriers, Obstacles and Limitations to Conducting Successful Business on the Internet Conference, pp. 482-491. ACM (2006)

34. Barclay, L.J., Kiefer, T.: Approach or Avoid? Exploring Overall Justice and the Differential Effects of Positive and Negative Emotions. Journal of Management (2013) 


\section{Appendix}

\begin{tabular}{|c|l|c|}
\hline Measures & \multicolumn{2}{|c|}{ Loading } \\
\hline Privacy (PR) & Personalization causes privacy problems: \\
\hline PR1 & Because it may keep track of my web behavior. & 0.97 \\
\hline PR2 & Because it may monitor my clicks and browsing records. & 0.96 \\
\hline PR3 & By exposing my personal information to unknown parties. & 0.76 \\
\hline Trust (TR) & The online vendor that offers personalized services: \\
\hline TR1 & Can be trusted at all times. & 0.84 \\
\hline TR2 & Can be counted on to do what is right. & 0.89 \\
\hline TR3 & Has high integrity. & 0.86 \\
\hline Emotions & In general, when I receive personalized services, I feel: \\
\hline \multirow{2}{*}{$\begin{array}{c}\text { Happiness } \\
\text { (HAP) }\end{array}$} & Satisfied & 0.87 \\
\cline { 2 - 3 } & Excited & 0.84 \\
\cline { 2 - 3 } & Curious & 0.57 \\
\hline \multirow{3}{*}{$\begin{array}{c}\text { Anxiety } \\
\text { (ANX) }\end{array}$} & Anxious & 0.78 \\
\cline { 2 - 3 } & Insecure & 0.74 \\
\cline { 2 - 3 } & Helpless & 0.71 \\
\cline { 2 - 3 } $\begin{array}{c}\text { Intention to } \\
\text { Purchase }\end{array}$ & Nervous & 0.78 \\
\hline \multirow{2}{*}{ INT1 } & In the future I intend to continue shopping. & 0.93 \\
\hline INT2 & My general intention to buy online is very high. & 0.88 \\
\hline INT3 & I will shop online in the future. \\
\hline
\end{tabular}

